\title{
Adoption of E-Commerce in the Agricultural and Fisheries Business Sector in Oman
}

\author{
Zahra Al-Busaidi ${ }^{1}$, Hemesiri Kotagama ${ }^{1 *}$, Houcine Boughanmi ${ }^{1}$, \\ Sunil Dharmapala ${ }^{2}$ and John Waelti ${ }^{1}$ \\ ${ }^{1}$ Department of Natural Resource Economics \\ College of Agricultural and Marine Sciences, Sultan Qaboos University \\ P.O. Box 34, Al-Khod 123, Sultanate of Oman \\ ${ }^{2}$ Department of Business Statistics, College of Commerce \\ and Economics, Sultan Qaboos University, \\ P.O. Box 20, Al-Khod 123, Sultanate of Oman
}

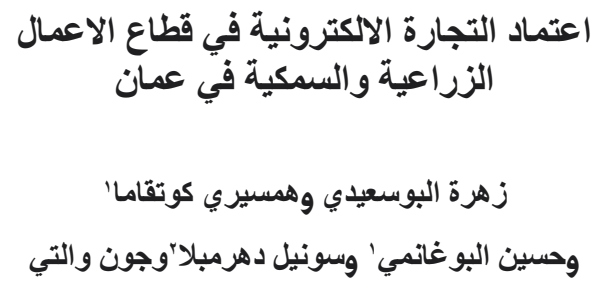

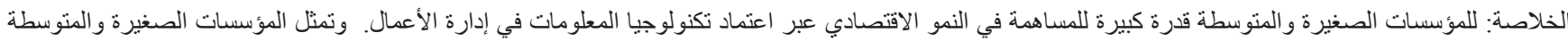

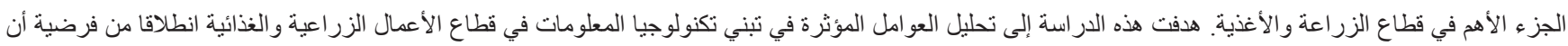

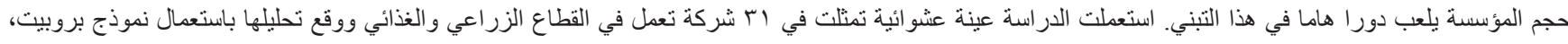

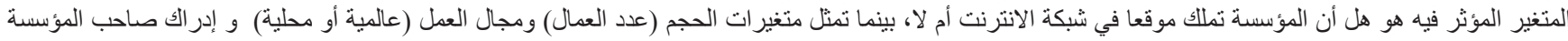

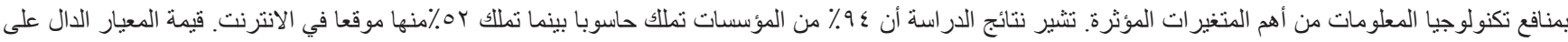

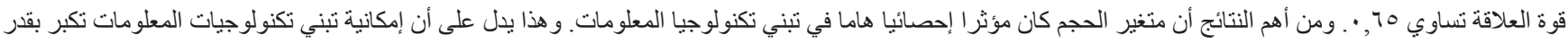

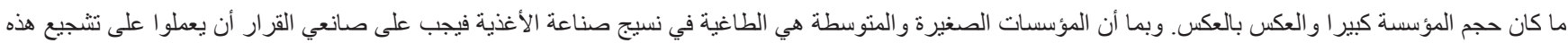

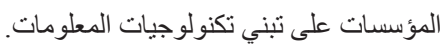

كلمات مفتاحية: التجارة الاكترونية، التبني، الاعمال الزراعية والسـمكية، نموذج بروبيت.

ABSTRACT: Small and Medium Businesses (SMB) have substantial potential to contribute to the growth of an economy through adoption of business related Information Technology. The Agricultural and Food Business (AFB) sector in Oman is dominated by SMBs. Factors influencing the adoption of e-commerce in the AFB sector in Oman were analyzed. The main hypothesis was that scale of the business influenced the adoption of e-commerce. Data were obtained from a random sample $(n=31)$ of AFBs in Oman and was analyzed using a Probit regression model. The dependent variable was whether the firm had a website, a proxy measure of adoption of e-commerce. The main independent variables were the scale of the business (measured by number of employees) and the scope of the business (international or national) and of variables related to manager's perception of benefits of adopting e-commerce. It was found that 94\% of AFBs in Oman used computers and about $52 \%$ of those had websites. The R-squared, of the estimated Probit regression model was 0.65 . The hypothesis that scale of the business influenced the adoption of e-commerce was not rejected, as the coefficient of the business scale variable was statistically significant $(\mathrm{t}=2.5, \mathrm{n}=31)$. The likelihood of adoption increases with increased scale of the business. On the converse this suggests that the likelihood of adoption of e-commerce by small and medium businesses is lower. Given the importance of small and medium businesses in the development of particularly the AFB sector of Oman, policy maker would have to promote and provide incentives to adopt e-commerce by SMBs.

Keywords: E-ecommerce, adoption, agricultural and fisheries business, Probit model.

\section{Introduction}

The government of Oman has embarked on a policy of economic diversification with an emphasis on improving the productivity of the agricultural and fisheries sector (International Trade Center, 2001). The Agricultural and Fisheries Business (AFB) sector in Oman is considered to consist predominately of Small and Medium Businesses (SMB). The government of Oman has recognized the potential of the SMBs to contribute to development, in terms of economic growth and job creation. However, the growth of the SMB has been lower than expectations (Bank Muscat, ud. 
Quoting a World Bank study). It is argued that adoption of business related Information Technology (IT) could provide small business companies with a competitive edge, which arises from improved management in general and linkages to global markets (Al-Qirim, 2004). Despite the national policy emphasis to promote the adoption of IT in various spheres of the economy, studies on the adoption processes of IT in Oman are not yet available. This study assesses the factors underlying the adoption of e-commerce in the AFB sector in Oman.

The paper is organized into five sections. The second section presents a brief literature review on the definition of e-commerce, benefits of e-commerce and factors that influence the adoption of e-commerce in the AFB sector. Section three presents the conceptual framework and the analytical methodology adopted in the study. Section four discusses and presents descriptive and statistical results of the analysis. Section five presents the conclusion and policy recommendations emanating from the study.

\section{Significance and Determinants of Adoption of E- Commerce}

IT is playing a significant role in promoting global economic growth. Efficiency of economic activities, particularly in a market economic context, depends on access to information. Access to relevant information empowers producers and consumers to make rational decisions, avoid information asymmetries thus improving market efficiency and social welfare. Industrial, service and agribusiness are all pursuing to adopt IT to gain competitive advantages. The major benefit of adopting ecommerce is the reduction of transaction costs in business. Henderson, et al. (2000) indicated that companies could expect to reduce spending by $9 \%$ with Business-toBusiness (B2B) procurement. E-commerce allows the possibility to explore a larger and more geographically diverse customer base (Henderson, et al., 2000 quoting Garcia, 1995). E-commerce provides consumers with more choices and more control over purchasing decisions (McFarlane, et al., 2003). This improves the efficiency of the functioning of the market, leading to reduced prices too.

IT encompasses forms of technology used in accessing, creating, storing, analyzing, exchanging and presenting information. The application of IT, particularly the use of the Internet in businesses activities has been broadly referred to as e-business. E-commerce is considered as a subset of e-business limited to the sale or purchase of goods and services over the internet (Henderson, et al., 2003). Chambers, et al. (2001) defined e-commerce as any business activity that uses the Internet. Further, according to McFarlane et al. (2003), these business activities could be conducted between businesses (B2B), businesses and consumers (B2C) and public sector and consumers. Economic and Social Commission for Western Asia (2003) defined e-commerce as everything which relates to doing business using internet or any electronic network.

Luecker (2000) identified agriculture as one of the top three sectors for growth in e-commerce. Despite this potential, the adoption rates of e-commerce within the agribusinesses have been relatively low vis-à-vis industrial and service businesses (Henderson, et al., 2000 and 2003; McFarlane, et al., 2003; Gul, et al., 2004). The United State Department of Agriculture in the National Agricultural Resources Management Study has shown that $29 \%$ of farms in the United States had Internet access and $15 \%$ of those had conducted some business over the Internet (Ehmake, et al., 2001). A survey done by Intertec (1999) reported that among high-income farmers in the US, $38 \%$ have been using the internet for e-mail, business, or to obtain information. Only a small fraction (less than $5 \%$ ) had made on line purchase. Other research indicates that about $40 \%$ of farm households in both Canada and the US use the internet, with about $30 \%$ of the use being specific to farming operations, and the remaining $70 \%$ for general information and entertainment purposes (Intertec, 1999). Hopkins and Morehart (2001) reported that the use of computers on farms has grown from $38 \%$ to $55 \%$ since 1997, while Internet use has grown from $13 \%$ to $43 \%$. As reported by Gregor, et al. (2002) quoting Muller (2001), in Germany $78 \%$ of farmers use internet for banking, $28 \%$ use it to purchase goods and $19 \%$ use it for selling goods and in Australia small businesses use it for communication via e-mail (82\%), to seek information about products $(67 \%)$ and get research data $(65 \%)$.

Henderson, et al. (2000) having examined adoption of e-commerce in Canada concluded that the major factors that influence the adoption of e-commerce by agribusinesses are the size of the firm and the international market scope of the firm. In addition, perceived efficiency benefits in specific functions (promotion and logistics) of the supply chain are significant factors explaining the adoption of e-commerce. The perception of ability to improve inventory management and increase sales is also a factor that contributes to improved adoption of e-commerce. They have concluded that most of the ecommerce is within B2B rather than B2C. Ehmke, et al. (2001) have studied the market for e-commerce services in agriculture in the state of Ohio in the USA. They reported that farmers do not have sufficient human capital and the affordability to adopt e-commerce. Furthermore, farmers may be resistant to change due to a commitment to tradition. They have also identified poor Internet connectivity in rural areas to be constraining the adoption of e-commerce in the agricultural sector.

Leroux, et al. (2001) have identified 3 factors that hinder adoption of e-commerce in agribusiness. These factors relate to the change in industry structure, product complexity and the personalized nature of transactions in agriculture. The consolidation of agribusinesses leads to a reduction in electronic coordination of fragmented markets, and large businesses may create barriers to the development of transparent electronic market places. Agricultural products are naturally diverse in quality and hence an adequate description is far from possible through electronic media. This complexity is further aggravated by consumer-preference changes for healthier foods, 
convenience, and diversity in food consumption. It has been argued that business relationships in the AFB sector to be more of one to one personalized relations and this would remain to be a barrier to adoption of e-commerce with non-personalized relationships. Gregor, et al. (2002) have examined the factors influencing the adoption of ecommerce in agribusiness in Queensland, Australia and they reported that among the reasons for the nonuse of e-commerce were the concerns about security and costs. They also reported that the primary reasons for engaging in e-commerce among Australian food companies include expansion of the sales base, efficiency, and keeping up with competitors. The primary reasons that inhibit adoption of e-commerce are: lack of personal contact, the ability of people to hack into the system, the unwillingness of customers to transact through the net, the perception of customers that the are not ready for e-commerce and the lack of expertise and knowledge. In addition, Gloy and Akridge (2000) included age and education of farmers as important factors that determine the adoption of ecommerce in the US.

According to McFarlane et al. (2003) the lack of privacy in e-commerce transactions was a major barrier to adopt e-commerce. Further firms with an international scope had a higher probability of adoption of e-commerce. The type of the product too substantially influences the adoption of e-commerce. Firms that sell products such as seed, feeds, grains and crops' inputs, and services such as consulting and financial services are more likely to adopt e-commerce. In this study the size of the firm was also found to be significantly influencing the probability of adoption of e-commerce. Henderson et al. (2000) have reported similar results.

Driedonks, et al. (2003) have studied the economic and social factors that relate to slow adoption of electronic media in B2B in the Australian beef industry. They have used two theoretical models, namely Kambil and Yan Heck's model of exchange process and Roger's diffusion theory. They concluded that perceived benefits of adoption have a larger influence on decision to adopt than the real economic benefits of adoption. The factors that delay the adoption of electronic markets are the loss of social capital (traditional ways of trading) and time taken for electronic market users to achieve critical mass. Henderson, et al. (2003) have examined e-commerce adoption in Canada. Firms that perceive higher benefits from logistical and inventory management through e-commerce are more willing to adopt it. Pearson and Grandon (2003) upon studying perceived strategic value and adoption of e-commerce in small and medium business in USA confirmed the findings of previous researchers that the perceived benefits from e-commerce adoption is a significant factor explaining adoption rates. Furthermore, they also found that other factors such as external pressure from the industry, organizational readiness to adopt are significant factors relating to adoption of e-commerce. Canavari, et al. (2003) having surveyed 208 agribusiness firms in Italy at all stages of the supply chain concluded that the level of adoption was low and particularly that small firms have not realized an advantage of its adoption. Most firms use the Internet more as a promotional tool and not as a selling and buying tool.

\section{Analytical Methods}

The main objective of this study was to establish the factors that cause adoption of e-commerce in AFBs in Oman. Past studies suggest that adoption of e-commerce would depend on internal factors that relate to the individual (owner or manager of the business) such as perception of benefits of e-commerce; the nature of the businesses such as whether B2B or B2C; and external factors such as government policy, legal aspects and supporting public infrastructure. Acknowledging the significance of small and medium business, particularly in AFB sector in Oman, a crucial factor that is of policy interest is the relationship of scale of the business and adoption of e-commerce. If one considers IT as scale neutral, it could be expected that likelihood of adoption of e-commerce would be the same among small, medium and large businesses.

Henderson, et al. (2000) have presented a model to assess adoption of e-commerce which largely considered that adoption is dependent upon perceived benefits of e-commerce on supply chain functions. An objective of a business firm is to improve efficiency through reducing the transaction costs on the supply chain functions. A supply chain performs seven functions. The seven functions include; manufacturing, logistics, promotion, financing, information, transaction and negotiation. If the use of e-commerce is perceived to be able to improve the efficiency of these functions, the likelihood of adoption of e-commerce by AFBs would be high. In this framework, the level of e-commerce adoption is a function of the perceived efficiency gains from the adoption of ecommerce in any of the seven functions of the supplychain. In this study, the Henderson et al. (2000) model was used with specific inclusion of the scale and scope of the business as internal factors that influence adoption of e-commerce. The external factors that influence adoption of e-commerce such as government policy, legal aspects, availability of supporting infrastructure were considered as constant. The notational representation of the above explanation is given in equation 1 .

$$
A D=f(M, L, P, F, I, T, N, G B, S B)
$$

where, $\mathrm{AD}$ is a measure of e-commerce adoption. The variables $\mathrm{M}, \mathrm{L}, \mathrm{P}, \mathrm{F}, \mathrm{I}, \mathrm{T}$ and $\mathrm{N}$ are measures of the perceived efficiency gains in the specific functions of the supply-chain due to adoption of e-commerce. These functions represent, respectively, Manufacturing (M), Logistics (L), Promotion (P), Finance (F), Information (I), Transaction (T) and Negotiations (N). GB is scope of business (international or national) and $\mathrm{SB}$ is scale of 
business measured as the number of employees. Based on the conceptual model presented above the following specific hypotheses were formulated: (i) Probability of adoption of e-commerce is higher among larger businesses than SMBs; (ii) Probability of adopting e-commerce is higher among business with international transactions than business with national transactions; and (iii) Probability of adopting e-commerce is higher among business where managers perceive benefits in improving supply chain functions with adoption of e-commerce.

Since the dependent variable is non-continuous, the probit model was used to estimate the relationship between adoption and factors hypothesized as influencing adoption. Firms were categorized into e-commerce users and non-users. Non users are firms which did not have a website and users were firms that had a website and used e-commerce in their normal business activities such as advertising, checking the mail and other advanced features, including online ordering or online ordering and payment.

Perception of benefits of adoption of e-commerce was obtained based on questions that related to a change in a function on the supply chain with the adoption of e-commerce. Responses were recorded on a 5-point Likert scale and were used as a continuous variable in the analysis following Gregor, et al. (2002). The firms were categorized based on the number of the employees following Henderson, et al. (2003) and Gul et al. (2004). The scope of the business was established based on whether major business activities relate to national or international markets.

The Probit model is an extension and an improvement of the linear probability model, which in the context of ecommerce adoption takes the following regression form:

$$
Y_{i}=\alpha+\beta X+\varepsilon_{i}
$$

where $X_{i}$ is a set of independent variables representing the value of attributes of the $i^{\text {th }}$ firm and $\alpha$ and $\beta$ are parameters to be estimated. Random error $\varepsilon_{\mathrm{i}}$ follows normal distribution with mean 0 and constant variance $\sigma^{2}$. The dependent variable $\mathrm{Y}_{\mathrm{i}}$ is a binary variable, which takes the value of 1 , if the company has a website and 0 if the company has no website

Since the expected value $\mathrm{Y}_{i}, \mathrm{E}(\mathrm{Yi})=\mathrm{P}(\mathrm{Y}=1)$, equation 2 above can be interpreted as describing the probability $\mathrm{P}(\mathrm{Y}=1)$ that a company will choose to have a website, given the information about the company's characteristics and managers attitude and opinions. The slope of the regression line measures the effect on the probability of adopting e-commerce of a unit change in the company's attributes. However, a weakness of the above linear probability model is that predicted values of $\mathrm{Y}_{\mathrm{i}}$ may lie outside the $(0,1)$ range, which is not possible if they are to be interpreted as probabilities. The solution to this problem is to transform the original model in such a way that predictions will fall in the $(0,1)$ interval for all $\mathrm{X}$. The basis of the transformation is to translate the values of the attributes $\mathrm{X}$, which may range in value over all the entire real line, to a probability, which range from 0 to 1 (see Griffith et al., 1992). This suggests the use of a cumulative probability function that may be presented as:

$$
P_{i}=F\left(\alpha+\beta X_{i}\right)=F\left(Z_{i}\right)
$$

where $F$ is a cumulative probability function and $Z_{i}$ is an unobservable index related to the choice of whether to have or not have a website and which is a random variable. If the cumulative probability function is normal then we have the Probit model ${ }^{1}$, which takes the following standardized form for a particular value $\mathrm{z}$.

$$
F(z)=P[Z \leq z]=\int_{-\infty}^{z} \frac{1}{\sqrt{2 \pi}} e^{-0.5 s^{2}} d s
$$

where $\mathrm{Z}$ is a random variable, which is normally distributed with mean zero and unit variance. By construction, the variable $\mathrm{P}_{i}$ will lie in the $(0,1)$ interval, representing the probability of the company's having a website. Since this probability is measured by the area under the standard normal curve from $-Z_{i}$, the event of having a website will be more likely to occur the larger the value of the index $\mathrm{Z}_{\mathrm{i}}$. In the probit model the conditional probability that a company will adopt-e commerce, given its attributes $\mathrm{X}_{\mathrm{i}}$ is equivalent to the probability that a standard normal variable will be less than or equal to $\alpha+\beta X_{i}$.

The Probit model is fundamentally non-linear and therefore estimating the parameters using Ordinary Least Squares (OLS) is inappropriate (Judge et al., 1981). The use of OLS leads to unbiased but inefficient estimators. Probit models are usually estimated using Maximum Likelihood Estimation technique, which now is routine in most modern econometric packages.

Ninety AFB firms were randomly selected from the Business Directory of Oman (2003). Based on the business firms listed in the Business Directory of Oman about 5\% are AFBs. Of the AFBs 39\%, 18\% and $42 \%$ are businesses supplying inputs in production and in marketing agricultural and fisheries products, respectively. The sample was stratified proportional to the above-mentioned types of businesses.

Data was obtained based on a questionnaire, which was faxed or mailed to the 90 firms. With 31 firms responding, the rate of response of the survey was $34.3 \%$. This compares well with similar studies such as Gregor et al. (2002), Henderson et al. (2000), and McFarlane et al. ${ }^{1}$ If the cumulative probability function is logistic, then we have the Logit
model. 
Table 1. Variables of the Probit model and hypothesized signs.

\begin{tabular}{|c|c|c|c|c|}
\hline Variable & & Description & $\begin{array}{c}\text { Nature of } \\
\text { quantification }\end{array}$ & $\begin{array}{l}\text { Hypothesized } \\
\text { sign }\end{array}$ \\
\hline \multicolumn{5}{|l|}{ Dependent } \\
\hline $\mathrm{Y}$ & & Whether having a website or not. & Have $=1$ or $\mathrm{No}=0$ & \\
\hline \multicolumn{5}{|l|}{ Independent } \\
\hline Manager's perception & Supply chain function & & & \\
\hline $\mathrm{X}_{1}$ & Logistics & $\begin{array}{l}\text { E-commerce improves firm's ability to mange } \\
\text { inventory }\end{array}$ & $\begin{array}{l}{ }^{1} \text { Likert scale } 1-5 \\
\text { (continuous) }\end{array}$ & - \\
\hline $\mathrm{X}_{2}$ & Information & $\begin{array}{l}\text { E-commerce enables easier access to business } \\
\text { information. }\end{array}$ & $\begin{array}{l}\text { Likert scale } 1-5 \\
\text { (continuous) }\end{array}$ & - \\
\hline $\mathrm{X}_{3}$ & Promotion & $\begin{array}{l}\text { Internet provides limited ability to communicate } \\
\text { product information. }\end{array}$ & $\begin{array}{l}\text { Likert scale } 1-5 \\
\text { (continuous) }\end{array}$ & - \\
\hline $\mathrm{X}_{4}$ & Negotiation & $\begin{array}{l}\text { Personal relationships with customers are difficult } \\
\text { to develop over the internet }\end{array}$ & $\begin{array}{l}\text { Likert scale } 1-5 \\
\text { (continuous) }\end{array}$ & + \\
\hline $\mathrm{X}_{5}$ & Transaction & E commerce reduces security of transactions. & $\begin{array}{l}\text { Likert scale } 1-5 \\
\text { (continuous) }\end{array}$ & + \\
\hline $\mathrm{X}_{6}$ & Promotion & E-commerce makes product comparison easier. & $\begin{array}{l}\text { Likert scale } 1-5 \\
\text { (continuous) }\end{array}$ & - \\
\hline $\mathrm{X}_{7}$ & Negotiation & $\begin{array}{l}\text { People/customers lack the required trust to use e- } \\
\text { commerce }\end{array}$ & $\begin{array}{l}\text { Likert scale 1-5 } \\
\text { (continuous) }\end{array}$ & + \\
\hline \multicolumn{5}{|l|}{ Type of business } \\
\hline $\mathrm{Z}_{1}$ & & Size of firm (in number of employees) & $\begin{array}{l}{ }^{2} \text { Likert scale } 1-5 \\
\text { (continuous) }\end{array}$ & + \\
\hline $\mathrm{Z}_{2}$ & & Business scope of firm & $\begin{array}{l}1=\text { international or } 0 \\
=\text { domestic }\end{array}$ & + \\
\hline
\end{tabular}

1. Likert scale on manager's perception: $1=$ strongly agree $2=$ agree $3=$ unsure $4=$ disagree $5=$ strongly disagree

2. Likert scale for size of firm: $1=1$ to 25 employees $\quad 2=26$ to 50 employees $\quad 3=51$ to 100 employees

$4=101$ to 500 employees $\quad 5=$ more than 500 employees

(2003), which reported a response rate of $38.5 \%, 19.1 \%$, and $29 \%$, respectively.

\section{Analysis}

\section{Descriptive Analysis}

Of the AFBs that were surveyed $45.2 \%$ were involved in production and/or marketing consumer products, $16.1 \%$ were involved in marketing inputs to farms, $29.0 \%$ were marketing both farm inputs and consumer products and $9.7 \%$ provide consultancy services related to AFBs. Most of the firms were SMBs. Twenty nine percent of the firms employed up to 25 employees, $10 \%$ employed 26 to $50,23 \%$ employed 51 to $100,38 \%$ employ more than 100 employees. It was revealed that $19 \%$ of the firms were public, $77 \%$ are privately owned, and $1 \%$ was cooperatives and $3 \%$ had not responded. Most of the firms that responded to the survey were B2C. About $80 \%$ of the firms were involved with international business activities. Only 6 percent of firms did not use a computer. This compares well with the level of computer use in Queensland, Australia, where 95\% of agribusiness are reported to have computers (Gregor et al., 2002). Fifty percent of the surveyed firms had a web site and adopted e-commerce.

\section{Probit Regression Analysis}

As indicated earlier, the dependent variable represents whether a firm has a website $(\mathrm{Y}=1)$ or not $(\mathrm{Y}=0)$. The independent variables that were used are given in Table 1 with their expected signs.

The estimated statistics of the probit model are given in Table 2. The estimated model has a reasonably high R-squared (0.65) indicating that the selected variables explain about $65 \%$ of the variation in adoption of ecommerce.

Among all the variables included in the model, only $\mathrm{Z}_{1}$, which is the size of firm, was significant at $5 \%$ level of significance. Thus the analysis suggests that the only variable that significantly influences the adoption of ecommerce is the size of the company. Larger companies are more likely to adopt e-commerce than small and medium business. The small and medium AFB firms in Oman, which are significant contributors to growth of 
Table 2. Results of the Probit analysis.

\begin{tabular}{|c|c|c|c|c|}
\hline & & Estimate & Standard Error & t- statistic \\
\hline $\mathrm{R}^{2}$ & & 0.65321 & & \\
\hline Constant & & -7.4998 & 4.3515 & -1.7234 \\
\hline Independent Variables & Description & & & \\
\hline \multicolumn{5}{|l|}{ Manager's perception } \\
\hline $\mathrm{X}_{1}$ & E-commerce improve firm's ability to mange inventory & 1.1675 & 0.7330 & 1.5927 \\
\hline $\mathrm{X}_{2}$ & E-commerce enables easier access to business information. & 1.2590 & 0.7700 & 1.6349 \\
\hline $\mathrm{X}_{3}$ & $\begin{array}{l}\text { Internet provides limited ability to provide product } \\
\text { information. }\end{array}$ & -0.7015 & 0.4872 & -1.4398 \\
\hline $\mathrm{X}_{4}$ & $\begin{array}{l}\text { E-commerce makes maintaining personnel relationship } \\
\text { difficult. }\end{array}$ & -0.7486 & 0.8439 & -0.8870 \\
\hline $\mathrm{X}_{5}$ & E commerce reduces security of transactions. & -0.5032 & 0.6286 & -0.8005 \\
\hline $\mathrm{X}_{6}$ & E-commerce enables product comparison easier. & -0.3122 & 0.5046 & -0.6188 \\
\hline $\mathrm{X}_{7}$ & People/ customers lack the required trust to use e-commerce & 0.3829 & 0.5172 & 0.7403 \\
\hline \multicolumn{5}{|l|}{ Type of business } \\
\hline$Z_{1}$ & Size of firm (in number of employees) & 1.3035 & 0.5201 & 2.5059 \\
\hline $\mathrm{Z}_{2}$ & Business scope of firm & 2.0168 & 1.5717 & 1.2832 \\
\hline
\end{tabular}

the AFB sector, have not been able to adopt and benefit from e-commerce despite substantial public investments on information technology. Benefits of IT could be best achieved only if a critical mass of business adopts the technology. Hence the government of Oman needs to encourage small and medium businesses to adopt ecommerce.

\section{Conclusion}

The major variable that explains the adoption of ecommerce is the scale of the business. The findings of the study highlight the need for the government to undertake measures to promote e-commerce, among SMBs, such that business productivity improves and returns to public investments on information technology is optimized. These recommendations are congruent with the recommendation by the ESCWA (2003) on Development of e-commerce Sectors in the Arab Region.

\section{References}

Al-Qirim, N.A.Y. 2004. Electronic Commerce in Small and Medium Sized Enterprises: Frameworks, Issues and Implications, Idea Group Publishers.

Business Directory of Oman 2003. Chamber of Commerce, Sultanate of Oman.

Driedonks, C.F., S. Gregor and A. Wassenaar. 2003. Economic and social analysis of the adoption of $b 2 b$ electronic marketplaces. A case study in the Australian beef industry. International Journal of Electronic Commerce 9:49-72.

ESCWA. 2003. Economic and Social Commission for Western Asia Secretariat. Development of e- commerce sectors in the arab regions. Beirut. http: //www.escwa.org.lb/wsis/conference/documents/19-ebusiness.pdf.

Ehmake, C., S. Ernst, J. Hopkins and L. Tweeten. 2001. The market for e-commerce services in agriculture Selected Paper for the AAEA Annual Meeting, Chicago, Illinois. http://www.agecon.purdue.edu/cab/research/ articles/ecommarket.pdf.

Goly, B.A. and J.T. Akridge. 2000. Drivers of internet adoption on large U.S farms and implications for agribusiness. Presented at 2000 IAMA World Food and Agribuisness Forum, Chicago, Illinois. htttp: //www.ifama.org/conferences/2000congress.

Gregor, S., D. Menzies and J. Rolfe. 2002. Influences on engagement in e-commerce in agribusiness: an empirical study. ITiRA Conference, Rockhampton, 27-28 August, pp285-296. http://ecocomm.anu.edu.au/ disciplines/ECOM/ETPaper2.pdf.

Griffiths, W.E., R.C. Hill and G.G. Judge. 1981. Learning and Practicing Econmometrics. John Wiley and Sons. Inc, USA,

Gul, A., S. Mutlu and T. Bal. 2004. Information in food industry in Cukurova of Turkey. Information Technology Journal 3(2):133-138.

Henderson, J., F. Dooley and J. Akridge. 2000. Adoption of e-commerce strategies for agribusiness firms. Selected Paper at the American Agricultral Economics Accosiation Annual Meeting, Tampa, FL. http://www.agecon.purdue.edu/cab/research/articles/ ecommerce.pdf.

Henderson, J., Dooley, F. and Akridge, J. 2003. Internet and e-commerce adoption by agricultural firms. Paper 
Presented at the RSS 2003 Annual Meeting, Montreal, Canada.http://www.ruralsociology.org/annualmeeting/2003/HendersonJason.pdf.

Hopkins, J. and Morehart, M. 2001. Economic research service, United States Department of Agriculture. http:/ /www.ers.usda.gov/publications/agooutlook/nov2001/ ao286f.pdf.

International Trade Center. 2001. An overview of the managerial concerns in international trade: economic and trade policy issues, a background note. Paper Presented as Kick-Off Meeting, Sultanate of Oman, Muscat. http://www.intracen.org/worldtradenet/docs/ networking/country_papers/paper_oman.pdf.

Intertec Publishing Corporation. 1999. A2k ag beyond 2000. http://www.ifama.org/conferences/2000Congress/ Forum $\% 20-\%$ Final $\% 20$ PAPERS/Area \%20III/ Thompson_Shelly2.PDF.

Leroux, N., S. Wortman Jr. and E. Mathias. 2001. Dominant factors impacting the development of business to business (b2b) e-commerce in agriculture. Paper Presented at the International Food and Agribusiness Management Association, World Food and Agribusiness Symposium, Australia, June 27-28, 2001.
http://www.ifama.org/conferences/2001Conference/ Papers/Area\%20III/Leroux_Nicole.PDF.

Little, D. 2000. Old MacDonald has a web site, Business Week E.Biz, May 15, pp83-88.

McFarlane, D., D. Chembezi and J. Befecadu. 2003. Internet adoption and use of e-commerce strategies by agribusiness firms in Alabama. Department of Agribusiness. Alabama A\&M University. Paper Presented at the Southern Agricultural Economics Association Annual Meeting, Mobile, Alabama. http://www.webspace.aamu.edu/ smallfarmers/AGB200308.pdf.

Muller, R.A.E. 2 001. E-commerce and enterpreneurship in agricultural markets. American Journal of Agricultural Economics 83:1243-1249.

Pacific Access. 2001. Yellow pages business index small and medium enterprises survey of computer technology and e-commerce in Australian small and medium businesses. Telstra Corp, July. http://www.about.sensis.com.au/ media/pdf/SBA-Archive/sba/tae/_YellowPagesSpecial Report_eCommerce_May99.pdf.

Received: May 2008

Accepted: March 2009 